\title{
Increase the reliability of power supply by using mechanical energy storage devices for low-power consumers
}

\author{
Nasullo Sadullaev ${ }^{1}$, Shukhrat Nematov ${ }^{1}$, and Mukhiba Gafurova ${ }^{2}$ \\ ${ }^{1}$ Energy-audit Department, Bukhara Engineering-Technological Institute, 200100 Bukhara, Uzbekistan \\ ${ }^{2}$ Machinery and equipment of light industry Department, Bukhara Engineering-Technological Institute, 200100 Bukhara, Uzbekistan
}

\begin{abstract}
The article analyzes the possibilities of using wind energy in Uzbekistan and studies the possibility of using energy storage devices to build a reliable electricity supply in the regions. In areas with weak winds, a device that first stores wind energy and then generates alternating electricity has been proposed. Energy storage systems have been analyzed, and it is recommended to use mechanical energy storage systems in the energy system consisting of renewable energy sources in the Republic of Uzbekistan. It has been noted that the use of such devices is particularly effective in areas far from centralized power supply, where power supply is not available or where reliability is low. An experimental model of a mechanical energy storage device using an elastic cord braid in a storage system and some equations for its design are given. The possibility and necessity of using this storage system is highly valued in our country. Despite the low power of the original model of the device, it is possible to achieve high results in the future by conducting research in this area and changing the type and composition of the elastic cord. This article presents the results of preliminary research on the development of a new design of mechanical energy storage devices using mechanical elastic cord.
\end{abstract}

\section{Introduction}

In recent years, a number of laws and decisions on the development of alternative energy sources has adopted in Uzbekistan. Their implementation requires the exploration of opportunities for the exploration and efficient use of renewable energy sources in our region. At present, the Republic pays more attention to the use of alternative energy sources, mainly solar energy, and significant progress has been made in this area. The analysis shows that we have enough opportunities to use wind energy. Today, the country's winds atlas has been compiled. According to this map, the total capacity of wind energy is 2.2 million tons of fuel equivalent. Its technical capacity is estimated at 0.427 million tons of fuel equivalent. Seventy-five percent of the country's land is unusable for wind power generation. This includes flat lands, where the winds are seasonal. The weak and unstable nature of wind in our region in most areas (Figure 1) has a negative impact on the simultaneous energy production of wind power plants (WPP) $[1,2,3]$. Modern WPPs works optimally at speeds from $5 \mathrm{~m} / \mathrm{s}$ to $25 \mathrm{~m} / \mathrm{s}$. Therefore, relatively little research is being done in the field of energy extraction at low speed flows.

This, in turn, promotes the idea that for low-power consumers, the energy of weak flows is first stored and then generated when electricity is needed [4,5]. In remote areas of the country, in the fields, in the deserts, it is expensive the transmission of electricity to remote areas who are engaged in animal husbandry or agriculture. Therefore, the installation of such alternative energy sources in these areas will provide economic efficiency. The use of these energy storage systems can also be used in reliable power supplies for measuring devices used in biological wastewater pollution control systems located in remote areas [6]. However, energy consumption in these areas is low and short-lived. For example, $2,2 \mathrm{~kW}$ electric motors installed in many water supply companies in remote areas run 30 minutes a day.

The use of energy storage devices is economically beneficial in countries with high electricity prices. In Uzbekistan, an increase in electricity prices is expected in the future due to the transfer of electricity production to the private sector and an increase in prices for fuel and energy resources. This indicates that in the future, the use of energy storage in Uzbekistan may be costeffective. Currently, due to the low cost of electricity in the country, it is efficient to use only cheap energy storage devices. Mechanical energy storage devices (MESs) are also cheap energy storage devices at a recognized cost of stored energy [7-9].

As of 2017, the installed capacity of energy storage units around the world was $176 \mathrm{GW}$. Pumped storage power plants account for the $169 \mathrm{GW}$ installed capacity of energy storage facilities $[10,11]$. This increase in the share of pumped storage energy storage was due to several factors that were positively different from other storage devices. The most important factor is the cost of 
stored energy, which is several times cheaper than other storage devices.

Many scientists around the world are doing a lot of research on energy conservation using the elastic strength of materials. Federico Rossi and others have argued that mechanical energy storage devices can be an effective tool for short-term and high-power consumers of electricity [12]. Such devices can be effectively used not only in power generation, but also in systems where mechanical work is performed.

A number of scientists are conducting research on the creation of a high-density mechanical energy storage device using the elastic force of carbon nanotubes. According to the researchers, 1,76 MJ of energy can be stored using $1 \mathrm{~kg}$ of carbon nanotubes [13]. The capacity and life of the energy storage system that uses these materials depends on the type of carbon nanotubes used in the system. In a study by Ftenakis, Zacharias and his group, carbon nanotubes were tested at hydrostatic pressures of several tens of GPa and found that, under optimum conditions, this technology could be used to create 4-10 times more powerful energy storage devices than lithium-ion batteries [14].

\section{Methodology}

A weather station of the MISOL company has been installed at the Bukhara Engineering-Technological Institute. The weather station automatically stores wind speed, direction and specific intensity of sunlight. It is very difficult to predict the generation of energy flows in renewable energy sources and energy production cannot be controlled. Consequently, consumers may experience imbalances in load schedules and power generation times. Figure 2 shows a graph of the electricity load for time intervals when demand is high during the day and the wind and solar power generated during these time intervals. That is, at 06:00 - 09:00, 18:00 - 23:00, 12:00 13:00 the consumer has a high demand for electricity, but, as can be seen from the diagram, there are not always intervals of renewable energy flows at such time (Figure 2).

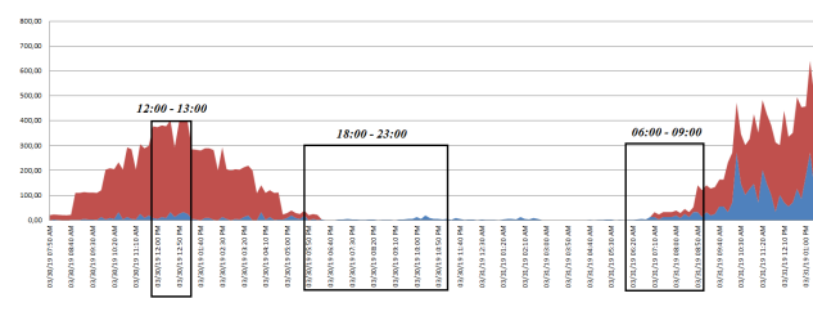

Fig. 2. The potential of solar and wind energy in the region from 06:00 to $09: 00$, from 18:00 to $23: 00$ and from 12:00 to 13:00.

Using energy storage devices is a more efficient method in cases where electricity consumption and associated energy flows are disproportionate. Because in nature we are able to store energy in periods of time when the generation of energy flows is high. During power outages, the use of energy storage devices is an effective way to improve the reliability of power supply.
The use of energy storage devices in electricity consumers will create opportunities for improving the quality of energy and the use of electricity in emergencies.

The use of battery devices in energy storage systems is also widespread in the world today. However, the use of batteries has a high sensitivity to external temperatures, the cost of the recycling process, the limited reserves of natural resources used for the production of batteries and the release of toxic substances into the environment during their production, and several other shortcomings. Therefore, the use of rechargeable batteries may be significantly reduced in the future [15].

The fact that mechanical energy storage devices have a simple structure, the relatively low cost of stored energy, increases the relevance of their use. Before using mechanical energy storage devices in Uzbekistan, there is a need to thoroughly analyze and study the world experience in the application of this technology. Because we need to study the advantages, disadvantages, disadvantages and adaptability of this technology to the climate of our region, and pay special attention to these aspects in the future use of this technology [16-20]. There are many types of materials that can replace raw materials in mechanical energy storage systems. Therefore, we can effectively implement the localization of production of such systems in our country. In the Republic of Uzbekistan, the efficiency of the use of batteries is underestimated due to low electricity prices and unfavorable climatic conditions in some areas.

Mechanical energy storage is one of the simplest structured energy storage systems that has been used for a long time. In the world, these devices are studied as energy storage devices of potential and kinetic energy [21-24]. In such systems, the stored mechanical energy can be converted into mechanical energy or electrical energy.

\section{Result}

Long-distance electric power transmission costs are high for livestock or agriculture farms located in remote areas of the country, such as pastures, deserts.

The main idea of the proposed design is to accumulate weak energy flows in the form of potential energy in elastic elements during no electricity consumption and smoothly use it, if necessary, to generate electricity with constant voltage and frequency. In some places, energy consumption is usually 200-300 watts for 2-3 hours a day. Mechanical energy storage devices accumulate the remaining 21-22 hours of weak energy flows. This uses weak winds or water currents. The accumulated mechanical power of the flow is about 50-70 W, and the energy stored in 20-22 hours allows to provide consumers with $200-300 \mathrm{~W}$ in $2-3$ hours. In this case, when there is a need for electricity, the accumulated energy is generated by AC electricity with a voltage of $220 / 380 \mathrm{~V}$.

Advantages of the device over other alternative energy sources are as follows: 
1. The cost of the device is much (at least 2 times) cheaper than the cost of other energy storage systems.

2. Lack of complex devices in the system (rectifier, accumulator, inverter, transformer).

3. Non-use of fuel and energy resources in the production of electricity.

4. Environmentally friendly production of electricity.

5. No need for power lines and transformers.

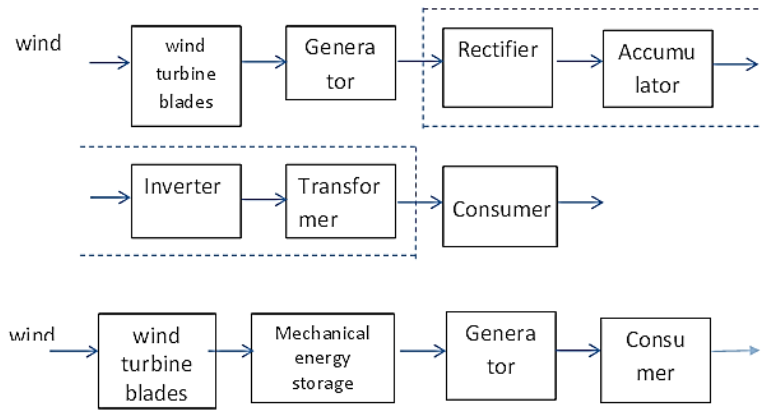

Fig. 3. Comparison of conventional and proposed power systems.

An energy device for low-power consumers, which provides low-speed energy flows, has been created at the Bukhara Engineering-Technological Institute. The device allows accumulating small low-speed energy flows during the day and using them in a short time. That is, the stored energy in the same amount is transferred to the alternator, which produces alternating current. In fig. 2 the structural design of the device is shown. Using wind or a flow of water, special mechanisms are used to wind the elastic rope (5) from a small drum (3) onto a drum (2) of a larger diameter by means of a gear wheel (10). In this case, mechanical energy is accumulated in the form of potential energy due to the stiffness of the elastic rope. The discs are of the same diameter 4 and are threaded, guarantees that the cylinders rotate opposite each other; and that the elastic rope is wound from one cylinder to the next. The rollers $(14,15)$ connected to the disc (4) together ensure a smooth transfer of the rope. During the accumulation of mechanical energy, the generator (11) is switched off via the gear wheels (6).

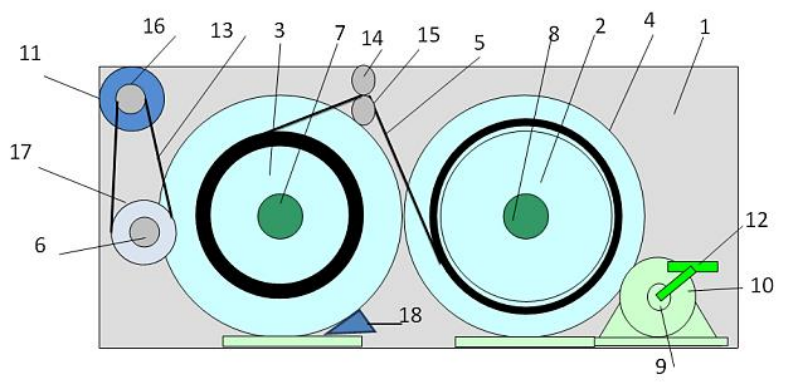

Fig. 4. Mechanical energy storage device.

When power is required, the gear drive (9) is disconnected and connected to the generator disk (4) through another gear drive (6). The stored energy is evenly consumed to generate alternating current at the generator output. It is also possible to accumulate mechanical energy using special pedals (12) in the absence of energy flows.

We determine the conditions necessary for the device to operate at a given power. The mechanical power required by a small cylinder to rotate the generator at a given speed is determined from the following expression, $\mathrm{kW}$ :

$$
P_{d 2}=\frac{P_{g e n}}{\eta_{g e n} \cdot \eta_{b . t} \cdot \eta_{g}}
$$

where $\eta_{g e n}, \eta_{b . t}, \eta_{g}$ are useful operating factors of the generator, belt transmission and gears.

In this case, the torque on the cylinder is determined as follows, $\mathrm{N} \cdot \mathrm{m}$ :

$$
M_{d 2}=F_{e} \cdot R_{d 3}=k \cdot \Delta l \cdot \frac{D_{3}}{2}
$$

where: $\mathrm{F}_{\mathrm{e}}$ - elastic rope gravity, $\mathrm{N} \cdot \mathrm{m} ; \mathrm{R}_{\mathrm{d} 3}$ - average radius of cylinders, $\mathrm{m} ; \mathrm{k}$ - is the stiffness of the elastic rope, $\mathrm{N} \cdot \mathrm{m} / \mathrm{m} ; \mathrm{D}_{1}$ - elongation of elastic rope, $\mathrm{m}$

The amount of accumulated mechanical energy that allows the generator to operate at a given power, $\mathrm{kWh}$ :

$$
W_{s t o r}=P_{d 2} \cdot t_{s t o r}
$$

It can be seen from the expression that even with a weak input power of the device, the required amount of energy can be accumulated by increasing the energy storage time. The output energy depends on the power flow and the time spent on heating energy.

We analyze the factors affecting the production of high-quality electricity in the device. We determine the total length of the rope that provides energy storage.

$$
L=l_{0} \cdot N=l_{0} \cdot \frac{W_{\text {stor }}}{W_{0}}=\pi \cdot D_{0} \cdot \frac{W_{\text {stor }}}{W_{0}},
$$

where 10 is the length of the winding rope wound on a small cylinder, m; Number of rooms, pcs.; $\mathrm{W}_{0}$ is the potential energy stored by the twisted rope, which is determined from the following expression:

$$
W_{0}=\frac{k \cdot \Delta l^{2}}{2}
$$



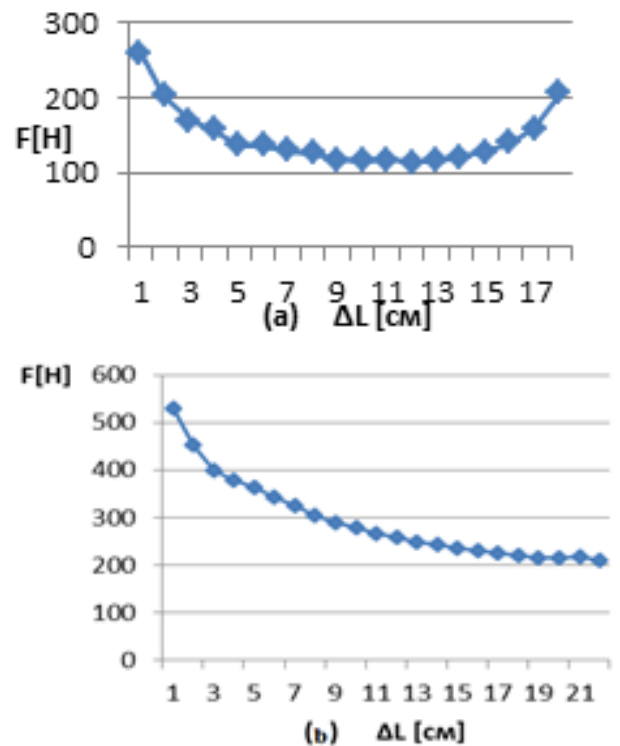

Fig. 5. The length of the elastic rope (a) $d=10 \mathrm{~mm},(b) d=15$ $\mathrm{mm}$.

From the above expressions it can be seen that the quality and quantity of the output voltage of the alternative energy source depends on the properties of the elastic rope. Small $(100-500 \mathrm{~W})$ power supplies can be used with elastic ropes used in sports. Figure 2 (a) shows the stiffness of multi-strand ropes with a diameter of $10 \mathrm{~mm}$, and Figure 2 (b) shows the rigidity of monolithic rubber elastic ropes with a diameter of 15 $\mathrm{mm}$. As can be seen from the figures, the stiffness of the rope is non-linear and negatively affects the output voltage of the source. This negative effect can be reduced by maintaining a constant tension of the elastic rope in the energy source.

To fulfill this requirement, two rollers were installed on the toothed disk of the snare drum by means of a toothed connection (Fig-2. 14, 15). The diameter of the rollers and the number of gears are chosen so that the length of the rope coming out of the roller is the same as that of the opening rope and there is no tension in this area. The rollers pull the rope in such a way that the rope wrapped around the big cylinder has the maximum tension.

A three-dimensional model of the device was developed to assess the capabilities of the device, assess the mechanical stresses, and work processes in the elements of the device. The 3D model was created in the Compass 3D program.

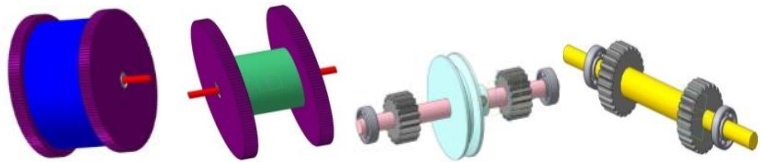

a)

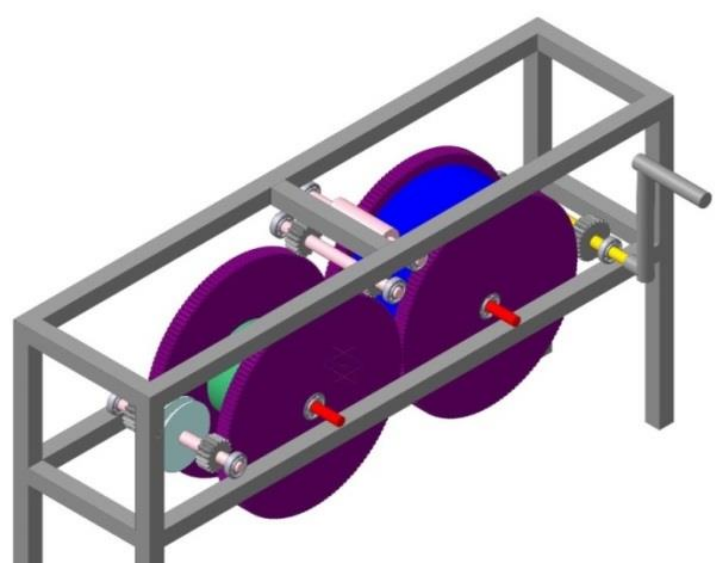

b)

Fig. 6. A virtual model of a mechanical energy storage device designed in the KOMPASS 3D program. a) Details of the device. b) General view of the device.

Experimental studies have shown that the stability of the value of the alternating current frequency and output voltage from the mechanical energy storage device increased by $15-20 \%$. On the picture. An experimental model of a mechanical energy reservation device for low-power consumers is presented.

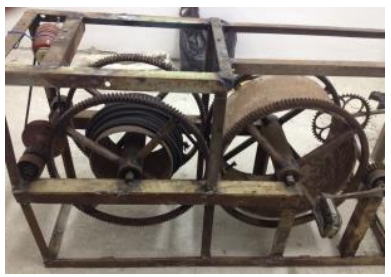

a)

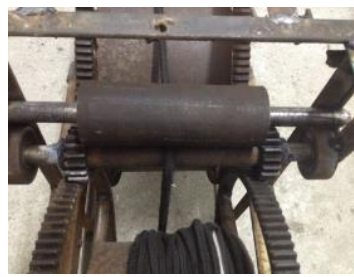

b)
Fig. 7. a) Experimental model of mechanical energy storage device; b) Cylinders that control the uniform winding of the elastic cord.

It is planned to use an axial generator consisting of neodymium magnets in the energy storage device. The number of poles of this generator has been increased, and therefore the number of rated revolutions has been reduced. An experimental model of this generator has been created. The generator efficiency was estimated from the output parameters obtained in the experimental model. Research is currently underway to improve the output parameters [25-27]. 


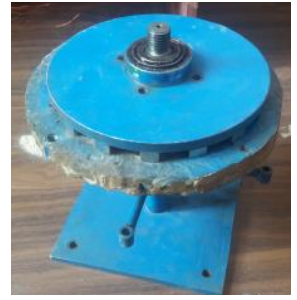

a)

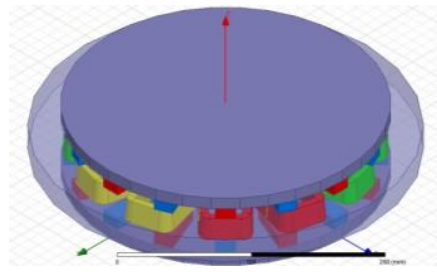

b)
Fig. 8. a) Experimental model of axial-flux generator; b) Virtual model of axial-flux generator.

\section{Conclusion}

The use of energy storage is an effective way to meet short-term electricity demand in remote areas where power supply reliability is low or where there is no electricity. The use of centralized power supply in these territories is ineffective due to the high cost of building the power grid and increasing losses in the transmission network. Most of the Republic of Uzbekistan consists of steppes with low wind speeds. Low wind speeds cannot be used directly for power supply. Therefore, it is recommended to accumulate and then use these slow wind flows. Due to the rise in summer temperatures in Uzbekistan, the use of traditional rechargeable batteries causes a lot of inconvenience. Using mechanical energy storage instead of rechargeable batteries can eliminate these inconveniences. In the proposed device, the accumulation of mechanical energy in order for a $500 \mathrm{~W}$ generator to work for 30 minutes, it must accumulate for 10 hours with a mechanical power of $50 \mathrm{~W}$. There is a growing need for this storage device for use in pipelines to regulate water and air flow (water and gas taps) in remote areas. In these control systems, the control devices cannot be controlled by the human factor and, of course, there is a need for electricity. Many of these control devices are located in deserts and steppes, and the supply of electricity to these points is considered inefficient. The proposed energy storage device is cost effective in the region. More research is needed to increase the power output of this mechanical energy storage device in order to improve its technical and economic performance. Currently, research is underway to determine the optimal type of rubber threads, a system for uniform transmission of mechanical energy for use in this storage of mechanical energy.

\section{References}

1. N.N. Sadullaev, A.B. Safarov, Sh.N. Nematov, R.A.Mamedov, Statistical Analysis of Wind Energy Potential in Uzbekistan's Bukhara Region Using Weibull Distribution, Applied Solar Energy, 55, 126-132 (2019) DOI: 10.3103/S0003701X19020105

2. N.N. Sadullayev, A.B. Safarov, Sh.N. Nematov, R.A. Mamedov, Research on facilities of power supply of small power capability consumers of Bukhara region by using wind and solar energy, Int.
J. Innovative Tech-nol. Exploring Eng., 8 (9S2), 229-236 (2019)

3. N.N. Sadullayev, A.B. Safarov, Sh.N. Nematov, R.A. Mamedov, A.B. Abdujabarov, Opportunities and Prospects for the using Renewable Energy Sources in Bukhara Region, Applied Solar Energy, $56 \quad(4), \quad 291-300 \quad$ (2020) DOI: 10.3103/S0003701X20040106

4. N.N. Sadullaev, U.T. Mukhamedkhanov, Sh.N. Nematov, F.O. Sayliev, Increasing Energy Efficiency and Reliability of Electric Supply of Low Power Consumers, International Journal of Engineering Trends and Technology, 68 (12), 43-47 DOI: $10.14445 / 22315381 /$ IJETT-V68I12P208

5. F. Lonis, V. Tola, G. Cau, Performance assessment of integrated energy systems for the production of renewable hydrogen energy carriers, E3S Web of Conferences, 197, $01007 \quad$ (2020) DOI 10.1051/e3sconf/202019701007

6. M.M. Idrisovich, Z.E. Kuziev, S.S. Nurov, S.S. Sidikov, Assessment of energy saving capabilities in air blowers of biological wastewater treatment plants, European Journal of Molecular \& Clinical Medicine, 7 (6), 1474-1486 (2020)

7. H. Hailemariam, F. Wuttke, Cyclic mechanical stability of thermal energy storage media, E3S Web of Conferences, 205, 07008 (2020) DOI: $10.1051 / \mathrm{e} 3$ sconf/202020507008

8. M.S. Guneya, Y. Tepe, Classification and assessment of energy storage systems, Renewable and Sustainable Energy Reviews, 75, 1187-1197 (2017)

9. R.A. Huggins, Energy Storage Fundamentals, Materials and Applications Second Edition (Springer New York, Heidelberg Dordrecht, London, 67-68) DOI: 10.1007/978-1-4419-1024-0

10. A.H. Alami, Mechanical Energy Storage for Renewable and Sustainable Energy Resources, Advances in Science, Technology \& Innovation, Springer Nature Switzerland AG (2020) DOI: 10.1007/978-3-030-33788-9

11. IRENA, Electricity Storage and Renewables: Costs and Markets to 2030, International Renewable Energy Agency, Abu Dhabi (2017)

12. F. Rossi, B. Castellani, A. Nicolini, Benefits and challenges of mechanical spring systems for energy storage applications, Energy Procedia, 82, 805-810 (2015) DOI:10.1016/j.egypro.2015.11.816

13. H. Zhan, G. Zhang, J.M. Bell, et all, High density mechanical energy storage with carbon nanothread bundle, Nat. Commun., 11, 1905 (2020) DOI: 10.1038/s41467-020-15807-7

14. Z. Fthenakis, Zh. Zhu, D. Teich, G. Seifert, D. Tomanek, Limits of mechanical energy storage and structural changes in twisted carbon nanotube ropes, Physical Review B., 88, 245402 (2013) DOI: 10.1103/PhysRevB.88.245402 
15. J. Eckart, Project Specialist, Inclusive Business Strategies, Global Leadership Fellow, World Economic Forum Geneva

16. B. Urishev, Selection of Parameters of Pumped Storage Power Plants at Large Pumping Stations for Water Use, Applied Solar Energy, 54, 477-480 (2018) DOI: 10.3103/S0003701X18060166

17. M. Sterner, I. Stadler (Eds.), Handbook of Energy Storage (Springer-Verlag GmbHGermany, part of Springer Nature, 821, 2019) DOI: 10.1007/978-3662-55504-0

18. J. Zhang, H. Seo, S. Kim, J. Ko, S. Kim, Experimental study of pipe-pile-based micro-scale compressed air energy storage (PPMS-CAES) for a building, E3S Web of Conferences, 205, 07012 (2020) DOI: $10.1051 / \mathrm{e} 3$ sconf $/ 202020507012$

19. M. Mirsaidov, I. Safarov, M. Teshaev, Dynamic instability of vibrations of thin-wall composite curvorine viscoelastic tubes under the influence of pulse pressure, E3S Web of Conferences, 164, 14013 (2020) DOI: 10.1051/e3sconf/202016414013

20. K. Voloshin, Y. Bocharov, E. Gyulikhandanov, S. Sopozhnikov, E. Kolpishon, V. Barilovich, B. Matisov, G. Topazh, B. Lyamaev, V. Nagornyy, Applicability of energy storage units to electric transport, E3S Web of Conferences, 91, 01006 (2019) DOI: 10.1051/e3sconf/20199101006

21. M.K. Teshaev, I.I. Safarov, N.U. Kuldashov, M.R. Ishmamatov, T.R. Ruziev, On the Distribution of Free Waves on the Surface of a Viscoelastic Cylindrical Cavity, Journal of Vibrational Engineering and Technologies, 8 (4), 579-585 (2019) DOI: 10.1007/s42417-019-00160-x

22. I. Wærnhus, C.S. Ilea, A. Vik, D. Tsiplakides, S. Balomenou, K. Papazisi, M. Schautz, Regenerative Energy Storage System for Space Exploration Missions, E3S Web of Conferences, 16, 10005 (2017) DOI: 10.1051/e3sconf/20171610005

23. S.C. Smith, P.K. Sen, B. Kroposki, Advancement of energy storage devices and applications in electrical power system, IEEE Power and Energy Society, General Meeting: Conversion and Delivery of Electrical Energy in the 21st Century, PES, 4596436 (2008) DOI: 10.1109/PES.2008.4596436

24. M.S.Z. Mat Desa, A. Hassan, A. Arsad, M. Yusop, Dynamic mechanical properties and morphology characteristics of rubber-Toughened poly(lactic acid, E3S Web of Conferences, 90, 01001 (2019) DOI: $10.1051 / \mathrm{e} 3$ sconf/20199001001

25. O.M. Brunhoeber, D. Arakkal, R. Ji, M. Miletić, L.E. Beckingham, Impact of mineral composition and distribution on the mechanical properties of porous media E3S Web of Conferences, 205, 02006 (2020) DOI: $10.1051 / \mathrm{e} 3$ sconf $/ 202020502006$

26. O. Toirov, A. Bekishev, S. Urakov, U. Mirkhonov, Development of differential equations and their solution using the simulink matlab program, which calculate the self-swinging of synchronous machines with traditional and longitudinal-transverse excitation, RSES 2020, E3S Web of Conferences, 216, $01116 \quad$ (2020) DOI: $10.1051 / \mathrm{e} 3$ sconf $/ 202021601116$

27. O. Toirov, K. Alimkhodjaev, N. Pirmatov, A. Kholbutaeva, Mathematical model to take into account the influence of saturation of the magnetic circuit on the starting characteristics of a synchronous motor, E3S Web of Conferences, 216, 01119 (2020) DOI: 10.1051/e3sconf/202021601119 